\title{
Steel Corrosion Behavior Measurement Based on Electrochemical Approach
}

\author{
Hongwei Feng ${ }^{1, *}$, Leilei $\mathrm{Cui}^{2}$ and Min Zhang ${ }^{3}$ \\ ${ }^{1}$ School of Civil Engineering and Architecture, Xinxiang University, Xinxiang, 453000, P.R. China \\ ${ }^{2}$ College of Civil Engineering, Huanghe S\&T University, Zhengzhou 450063, P.R. China \\ ${ }^{3}$ Zhengzhou University, Zhengzhou, 450063, P.R. China \\ *E-mail: fenghongweixx@126.com
}

doi: $10.20964 / 2016.06 .56$

Received: 6 March 2016 / Accepted: 4 April 2016 / Published: 4 May 2016

Concrete is an important material commonly used in the building. The exposure of the reinforced concrete in different environment could cause different rate of corrosion. Chloride ions and carbon dioxide are two major substances could accelerate the corrosion rate. In this contribution, we used the electrochemical methods for evaluating the corrosion rate of the two different types of concrete in the presence of chloride ions and carbon dioxide environment. Polarization resistance, polarization curves intersection and electrochemical impedance spectroscopy were applied for detail analysis. The results showed the corrosion rate of both concrete was similarly when exposed to carbon dioxide while the binder played an important role when the environment contained chloride ions.

Keywords: Cement; Corrosion; Concrete; Electrochemistry; Polarization resistance; Electrochemical impedance spectroscopy

\section{$\underline{\text { FULL TEXT }}$}

(C) 2016 The Authors. Published by ESG (www.electrochemsci.org). This article is an open access article distributed under the terms and conditions of the Creative Commons Attribution license (http://creativecommons.org/licenses/by/4.0/). 